\title{
Evaluation of the use of radiosonde humidity data to predict the occurrence of persistent contrails
}

Article

Published Version

Radel, G. and Shine, K. P. (2007) Evaluation of the use of radiosonde humidity data to predict the occurrence of persistent contrails. Quarterly Journal of the Royal Meteorological Society, 133 (627). pp. 1413-1423. ISSN 1477870X doi: https://doi.org/10.1002/qj.128 Available at https://centaur.reading.ac.uk/817/

It is advisable to refer to the publisher's version if you intend to cite from the work. See Guidance on citing.

Published version at: http://www3.interscience.wiley.com/journal/113388514/home

To link to this article DOI: http://dx.doi.org/10.1002/qj.128

Publisher: Royal Meteorological Society

All outputs in CentAUR are protected by Intellectual Property Rights law, including copyright law. Copyright and IPR is retained by the creators or other copyright holders. Terms and conditions for use of this material are defined in the End User Agreement.

www.reading.ac.uk/centaur 
Central Archive at the University of Reading

Reading's research outputs online 


\title{
Evaluation of the use of radiosonde humidity data to predict the occurrence of persistent contrails
}

\author{
G. Rädel* and K. P. Shine \\ Department of Meteorology, University of Reading, Reading, UK
}

\begin{abstract}
Regular visual observations of persistent contrails over Reading, UK, have been used to evaluate radiosonde measurements of temperature and humidity defining cold ice-supersaturated atmospheric regions which are assumed to be a necessary condition for persistent condensation trails (contrails) to form. Results show a good correlation between observations and predictions using data from Larkhill, $63 \mathrm{~km}$ from Reading. A statistical analysis of this result and the forecasts using data from four additional UK radiosonde stations are presented. The horizontal extent of supersaturated layers could be inferred from this to be several hundred kilometres. The necessity of bias corrections to radiosonde humidity measurements is discussed and an analysis of measured ice-supersaturated atmospheric layers in the troposphere is presented. It is found that ice supersaturation is more likely to occur in winter than in summer, with frequencies of $17.3 \%$ and $9.4 \%$, respectively, which is mostly due to the layers being thicker in winter than in summer. The most probable height for them to occur is about $10 \mathrm{~km}$. Copyright (c) 2007 Royal Meteorological Society
\end{abstract}

KEY WORDS ice supersaturation; contrails; radiosondes

Received 7 February 2007; Revised 6 June 2007; Accepted 8 June 2007

\section{Introduction}

Air traffic is expected to increase strongly in the near future and is therefore an area of major concern regarding its influence on global climate (e.g. IPCC, 1999; Marquart et al., 2003; Sausen et al., 2005). Apart from emitting greenhouse gases, persistent condensation trails (contrails) that form in the wake of an aircraft may influence the radiation budget of the Earth in a similar way as natural cirrus. In other words, they are presumed to cause a net warming as absorbed and reflected infrared radiation from the ground and lower troposphere outweighs the effect of more sunlight being reflected to space (e.g. Meerkötter et al., 1998; Minnis et al., 1999; Myhre and Stordal, 2001). Contrails form when hot and moist exhaust mixes with cold, drier ambient air; this increases the relative humidity (RH) and can lead to water saturation if the ambient air is below a critical temperature $T_{\mathrm{c}}$. The critical temperature is given by the Schmidt-Appleman criterion (Schmidt, 1941; Appleman, 1953; Schumann, 1996) and depends on the ambient pressure, humidity and temperature as well as engine dependent parameters. If the air is subsaturated with respect to ice, contrails persist for no more than a few minutes. However, in the case of supersaturation with respect to ice $\left(\mathrm{RH}_{\text {ice }}>100 \%\right)$ contrails can persist for up to several hours and can eventually even evolve into

\footnotetext{
* Correspondence to: G. Rädel, Department of Meteorology, University of Reading, Earley Gate, P.O. Box 243, Reading, RG6 6BB, UK.

E-mail: g.radel@ reading.ac.uk
}

extended cirrus clouds that are indistinguishable from natural cirrus (Minnis et al., 1998; Schröder et al., 2000; Mannstein and Schumann, 2005; Stubenrauch and Schumann, 2005).

In order to better understand and quantify the effect of persistent contrails on climate, a thorough understanding of the atmospheric conditions required for them to form is essential. Humidity and temperature measurements from radiosonde ascents may be a very valuable tool for this purpose, since they provide relatively regular measurements in space as well as in time with high vertical resolution. This is especially true for Europe and North America, regions where most air traffic currently occurs. The aim of this paper is to use humidity and temperature data from some of the routine radiosonde launch sites located in the UK and predict the presence of cold ice-supersaturated regions, which are a necessary condition for persistent contrails. These predictions are then compared with visual observations of contrails which have been made at the same time over Reading, southeast England.

Visual observations of contrails have been used previously to try to evaluate the atmospheric conditions necessary for them to form and persist. For instance, Jensen et al. (1998) measured temperature and humidity in situ during the aircraft campaign SUCCESS (Subsonic Aircraft: Contrail and Cloud Effects Special Study) and compared contrail formation and lifetimes observed from the same aircraft. However, less than 20 cases of persistent contrails were observed. Minnis et al. (2003) compared regular visual observations of persistent contrails 
over the US with temperatures and humidities measured by radiosondes on a monthly basis.

Several other studies have been performed evaluating different contrail production forecasts using radiosonde measurements and visual observations (e.g. Moss, 1999; Walters et al., 2000; Jackson et al., 2001) but these did not address the question of persistence of contrails. Stuefer et al. (2005) compared contrail observations over Alaska with uncorrected radiosonde measurements and performed a statistical analysis comparing different forecasts, also addressing the lifetime of contrails. However, the question of ice supersaturation was not discussed explicitly.

Spichtinger et al. (2003) identified and analysed icesupersaturated atmospheric layers using radiosonde data over Lindenberg, Germany, and compared them to satellite observations. The present study shows direct colocations of a high number of radiosonde measurements of such cold supersaturated atmospheric layers with visual observations of persistent contrails.

In the first part of this paper the selection of the radiosonde measurements and their treatment will be explained. An analysis of identified ice-supersaturated regions will be presented using a large amount of data from 2000-2006, showing properties such as frequency and height of occurrence, seasonal cycle and average thickness. In Section 3 the database of contrail observations will be introduced and observations will be compared with the predictions of cold supersaturated atmospheric regions from different radiosonde stations via $2 \times 2$ contingency tables. The results of a statistical analysis of these comparisons will be presented in Section 4.

\section{Analysis of radiosonde humidity measurements}

\subsection{Selection and correction of radiosonde profiles}

Radiosonde measurements of temperature and humidity from different stations in the UK have been analysed in order to detect atmospheric layers susceptible for the formation of persistent contrails. The main aim is to establish a correlation between visual observation of persistent contrails over Reading $\left(0.97^{\circ} \mathrm{W}, 51.45^{\circ} \mathrm{N}\right)$ with actual atmospheric conditions. Larkhill $\left(1.80^{\circ} \mathrm{W}, 51.20^{\circ} \mathrm{N}\right)$ was selected as the main radiosonde launch site, since at a distance of $63 \mathrm{~km}$ it is the closest site to Reading, providing data on a regular daily basis. Moreover, as Larkhill is located to the southwest of Reading, the actual distance between the radiosondes and the observations is often smaller due to prevailing south-westerly winds. For comparison, four additional UK stations were chosen which have all been providing regular data since at least 2000. This way, the temporal and spatial variations of atmospheric conditions could also be studied. These stations are: Herstmonceux $\left(1.80^{\circ} \mathrm{W}, 51.20^{\circ} \mathrm{N}\right)$, Nottingham $\left(1.20^{\circ} \mathrm{W}, 53.00^{\circ} \mathrm{N}\right)$, Camborne $\left(5.32^{\circ} \mathrm{W}, 50.22^{\circ} \mathrm{N}\right)$ and Lerwick $\left(1.18^{\circ} \mathrm{W}, 60.13^{\circ} \mathrm{N}\right)$.

Vaisala radiosondes of type RS80 have been used worldwide over a long time period and their measurement accuracy and systematic biases have been studied by several groups (Wang et al., 2002; Miloshevich et al., 2004). The type of radiosondes used in the UK over this period were Vaisala RS80-H sondes with most sites switching to the new type RS92 during the years 2005 or 2006, depending on the site. In the case of Larkhill, sondes of both types were used concurrently during the second part of 2005. Profiles of temperature and humidity recorded by the UK Met Office radiosondes were provided by the British Atmospheric Data Centre (BADC) prior to May 2005, and thereafter by the European Centre for Medium-Range Weather Forecasts (ECMWF) from the Global Telecommunication System (GTS) record. Only profiles with continuous temperature and humidity measurements up to at least $150 \mathrm{hPa}$ were used.

Relative humidity measurements in the upper troposphere are particularly challenging due to low temperatures and low water vapour concentrations. Different types of sondes are subject to different error sources, such as time lag, chemical contamination, sensor ageing, etc., resulting in the need for different bias correction methods. For instance, while the more widely-used Vaisala RS80A sondes show a large temperature-dependent error, this problem is much smaller for the RS80-H sondes used in the UK (Miloshevich et al., 2001, Wang et al., 2002). The main error source for these sondes is the chemical contamination originating from non-water molecules emitted from the packaging material that occupy binding sites in the sensor polymer, leading to a dry bias in the RH measurement. Wang et al. (2002) developed a correction method for this and other measurement biases (including temperature dependence, ground check and sensor ageing) which has been applied to the RS80-H data used in this study. The synoptic data used for the ground check correction was again obtained from BADC and, since May 2005, from ECMWF. The availability of these ground data at the radiosonde launch sites has been another criterion for the choice of the radiosonde sites. It was found that the correction that has to be applied to the RH measurements was small, i.e. lower in magnitude than $-5 \%$ for temperatures down to about $-30^{\circ} \mathrm{C}$ and up to about $-15 \%$ at $-70^{\circ} \mathrm{C}$. Relative corrections are largest for high relative humidities.

RS92 radiosondes were introduced by Vaisala in 2003 and much less information of their measurement accuracy exists in current literature. In a recent study by Vömel et al. (2007), however, a bias correction procedure was developed and has been adopted here. The calibration procedure has been improved significantly with respect to previous sonde types, but the RS92 sondes no longer have a radiation shield, making measurements susceptible to solar heating. This causes an important potential error source for this study since daytime measurements are essential in order to be comparable to visual observations of contrails. The radiation bias correction factors have been derived by Vömel et al. (2006) by comparing radiosonde measurements with a reference cryogenic frost-point hygrometer with radiosonde launches around noon in the tropics, at a very small solar zenith angle. 
The dependence of the radiation bias on this angle is unknown.

In the present study, therefore, this correction has only been applied to radiosonde launches between 10:00 and 14:00 GMT. This means that daytime measurements at larger solar zenith angles are probably under-corrected, but the development of a solar angle dependent correction for the radiation bias is beyond the scope of this paper. Figure 1 depicts the average size of the corrections applied to the RS80-H and RS92 radiosondes. For the latter, day- and night-time corrections are shown separately, stressing the importance of the radiation bias. The average correction applied to night-time measurements is of the same order of magnitude (about $-2 \%$ to $-4 \%$ ) as that for RS80-H sondes for temperatures down to about $-50{ }^{\circ} \mathrm{C}$. For colder temperatures, it however changes sign and becomes as large as $+13 \%$ at $-70^{\circ} \mathrm{C}$. In daytime, when the radiation bias is the dominant source of error, corrections are much larger for the RS92 sonde than for the RS80-H sondes: they start at about $-10 \%$ at $0{ }^{\circ} \mathrm{C}$ and rise to a maximum of about $-40 \%$ at $-60{ }^{\circ} \mathrm{C}$.

A residual uncertainty of the radiosonde humidity measurements are due to sensor icing, which is particularly important for the RS80-H sensors. When passing through a super-cooled area or cloud the sensor may ice over;

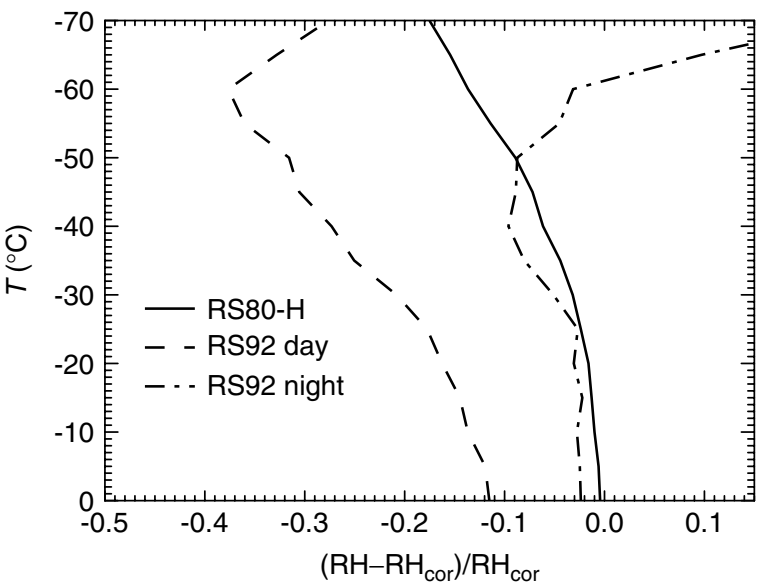

Figure 1. Average correction applied to radiosonde relative humidity measurements as a function of ambient temperature. Full line: RS80-H sondes, dashed line: daytime RS92 sondes, dash-dotted line: night-time RS92 sondes.

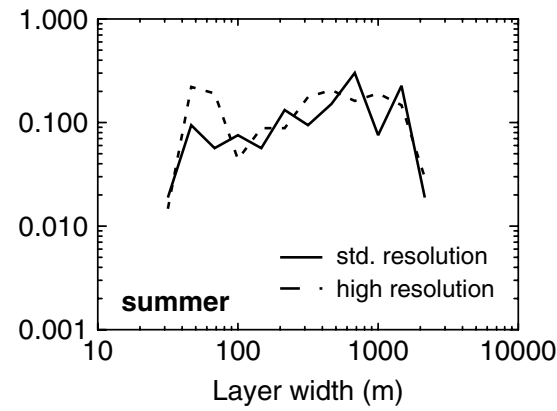

hence supersaturation may be measured for the rest of the ascent of the sonde even if the ambient air is not supersaturated with respect to the ice. The occurrence of this icing effect is difficult to spot for each profile. In order to have humidity profiles which are as clean as possible, we therefore restrict analyses of cold ice-supersaturated regions (CISSR) to the troposphere. For the quantitative analyses of Sections 2.2 and 2.3, we exclude all profiles that show very high RH measurements $(\mathrm{RH}>90 \%)$ above the tropopause. The tropopause pressures are taken from a climatology based on the ECMWF re-analysis, ERA40, with Simmons and Gibson (2000) providing monthly mean values for $5^{\circ} \times 5^{\circ}$ grid points.

\subsection{Vertical resolution of radiosonde data}

The standard resolution data from the UK Met Office radiosonde stations provide temperature and humidity measurements at a set of 20 standard pressure levels and at a varying number of intermediate levels. For the five stations studied here, the average vertical resolution in the upper troposphere is about $300 \mathrm{~m}$ or $30 \mathrm{hPa}$, with slightly better values for Larkhill of $250 \mathrm{~m}$ and $20 \mathrm{hPa}$. In addition to these so-called standard resolution radiosonde data, the UK Met Office provides a set of high resolution radiosonde data with a vertical resolution of about $50 \mathrm{~m}$ in the upper troposphere. This dataset was used to cross-check results, obtained with the standard data set. Figure 2 shows the distributions of the width of supersaturated atmospheric layers for the example of Herstmonceux, averaged over all data from 2002 for the two different resolutions for both summer (June-August) and winter (December-February). The two datasets give similar results for widths larger than about $150 \mathrm{~m}$, but the high resolution set shows, in addition, a large peak of thinner layers with an average width of about $50 \mathrm{~m}$. The overall mean of the width distributions are $42 \mathrm{hPa}$ or $1.0 \mathrm{~km}$ for the standard data, and $31 \mathrm{hPa}$ or $0.7 \mathrm{~km}$ for the high resolution set. The additional thin layers resolved only in the high resolution data change the number of supersaturated layers per atmospheric profile. Taking into account only profiles with at least one such layer, the average number of layers is 1.1 for the standard dataset compared to 2.3 for the high resolution data; if all profiles are considered, the corresponding numbers

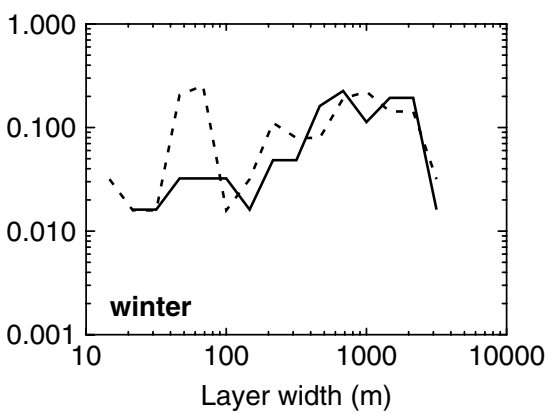

Figure 2. Distributions of the width of the supersaturated cold atmospheric layers derived from standard (full lines) and high resolution (dashed lines) data for summer (left) and winter (right). 
are 0.4 and 0.5 . The additional thin layers mostly belong to profiles that already have a supersaturated layer. The average height of the layers (base, centre and top) are, however, very similar for the standard and high resolution data, except perhaps in winter when a small difference for the mean centre and top heights can be observed. The high resolution data show slightly lower top and centre heights.

Table I summarizes these results. In the following, the standard dataset will be used due to its larger availability (high resolution data is, for example, not available for Larkhill), which means that the following results are valid for layers with a width of $\geq 150 \mathrm{~m}$. Results that do not concern the width of the layers, in particular those concerning temporal variations, are only marginally affected.

\subsection{Analysis of cold ice-supersatured regions}

The existence of CISSRs, which predominantly occur in the troposphere, is assumed to be a condition for persistent contrails to form (e.g. Schumann, 1996). The aim is therefore to determine the frequency, time and height at which CISSRs form, and to determine the thickness or horizontal extension of atmospheric layers formed under these conditions. The criteria we impose to identify CISSRs are: the layer must be supersaturated with respect to ice, i.e. $\mathrm{RH}_{\text {ice }}>100 \%$ and the temperature must be lower than a critical temperature $T_{\mathrm{c}}$, assumed to be $-40^{\circ} \mathrm{C}$. In principle, the value of $T_{\mathrm{c}}$ depends also on the propulsion efficiency of the aircraft engine, e.g. a higher propulsion efficiency leads to contrails being produced at higher temperatures (Schumann, 2000). The chosen value for $T_{\mathrm{c}}$ is broadly consistent with a propulsion efficiency of 0.3 , a typical value for modern aircraft flying in the upper troposphere (e.g. Schumann, 1996). $\mathrm{RH}_{\text {ice }}$ has been determined using the saturation water vapour formula (Sonntag, 1994).

Initially, the probability of finding $\mathrm{RH}_{\text {ice }}>100 \%$ within a given height range was computed as the ratio of measurements per profile that show supersaturation and the total number of measurements. The probability of an ice-supersaturated region averaged over all stations, years and heights from $6 \mathrm{~km}$ to the tropopause is $21.3 \%$, with a pronounced seasonal difference of $22.5 \%$ in winter (October-March) and $18.1 \%$ in summer (April-September). This agrees with observations of lower relative humidities in the upper troposphere in mid latitudes in summer (e.g. Soden and Lanzante, 1996; Stephens and Wittmayer, 1998; Kley and Phillips, 2000). These values can be compared to results of Vaughan et al. (2006) who identified ice-supersaturated atmospheric regions over Aberystwyth $\left(4.06^{\circ} \mathrm{W}, 52.4^{\circ} \mathrm{N}\right)$ using corrected Vaisala RS80-A sondes. In the height interval $6-8 \mathrm{~km}$, we find probabilities of $14.8 \%$ and $19.1 \%$ in summer and winter, respectively, compared to $8.2 \%$ and $18.2 \%$ in Vaughan et al. (2006). For the $8-10 \mathrm{~km}$ region the corresponding values are $20.6 \%$ and $25 \%$ in our analysis, compared to $13.2 \%$ and $24.3 \%$ in Vaughan et al. (2006). For winter these results agree very well with those of Vaughan et al. (2006); for summer they are about $50 \%$ higher.

Including the condition that the ambient air temperature is less than $-40^{\circ} \mathrm{C}$ gives the probability of a CISSR anywhere between $6 \mathrm{~km}$ height and the tropopause. These probabilities are shown in Figure 3 as a function of the calendar month averaged over the five stations for years 2000-2006 (right and left, full bold lines). To show the local and temporal variations, data for the five different stations averaged over all years (left) and for the seven years averaged over all stations (right) are also shown. The mean values of the probability that a CISSR will occur are $13.7 \%$ overall with $9.4 \%$ in summer and $17.3 \%$ in winter, showing a pronounced seasonal cycle which is clear both collectively and at each station individually (Figure 3). Minnis et al. (2003) used visual observations of persistent contrails over the US to derive contrail frequencies of $15.2 \%(1993-1994)$ and $12.4 \%$ (1998-1999). These absolute values cannot be compared directly to the frequencies of CISSRs; however, the seasonal cycles of persistent contrails found by Minnis et al. (2003) and of CISSRs found in this study are in very good agreement regarding the position and amplitudes of minimum (summer) and maximum (winter).

Table I. Comparison of characteristics of cold supersaturated atmospheric layers derived from standard and high resolution radiosonde data from Herstmonceux.

\begin{tabular}{|c|c|c|c|c|c|c|c|}
\hline & & \multicolumn{3}{|c|}{ Standard resolution } & \multicolumn{3}{|c|}{ High resolution } \\
\hline & & All & Winter & Summer & All & Winter & Summer \\
\hline \multirow{2}{*}{ Width (mean) } & $(\mathrm{hPa})$ & 42 & 59 & 31 & 31 & 37 & 25 \\
\hline & $(\mathrm{km})$ & 1.0 & 1.3 & 0.8 & 0.7 & 0.8 & 0.7 \\
\hline \multirow[t]{2}{*}{ Base height (mean) } & $(\mathrm{hPa})$ & 322 & 352 & 295 & 320 & 353 & 291 \\
\hline & $(\mathrm{km})$ & 8.6 & 7.9 & 9.3 & 8.7 & 7.9 & 9.4 \\
\hline \multirow[t]{2}{*}{ Centre height (mean) } & $(\mathrm{hPa})$ & 301 & 323 & 279 & 304 & 334 & 279 \\
\hline & $(\mathrm{km})$ & 9.1 & 8.6 & 9.7 & 9.0 & 8.3 & 9.7 \\
\hline \multirow[t]{2}{*}{ Top height (mean) } & $(\mathrm{hPa})$ & 280 & 294 & 263 & 289 & 315 & 266 \\
\hline & $(\mathrm{km})$ & 9.6 & 9.2 & 10.1 & 9.4 & 8.7 & 10.1 \\
\hline \multicolumn{2}{|c|}{ Number of layers per profile } & 0.4 & & & 0.5 & & \\
\hline \multicolumn{2}{|c|}{ Number of layers per profile if $>0$} & 1.1 & & & 2.3 & & \\
\hline
\end{tabular}



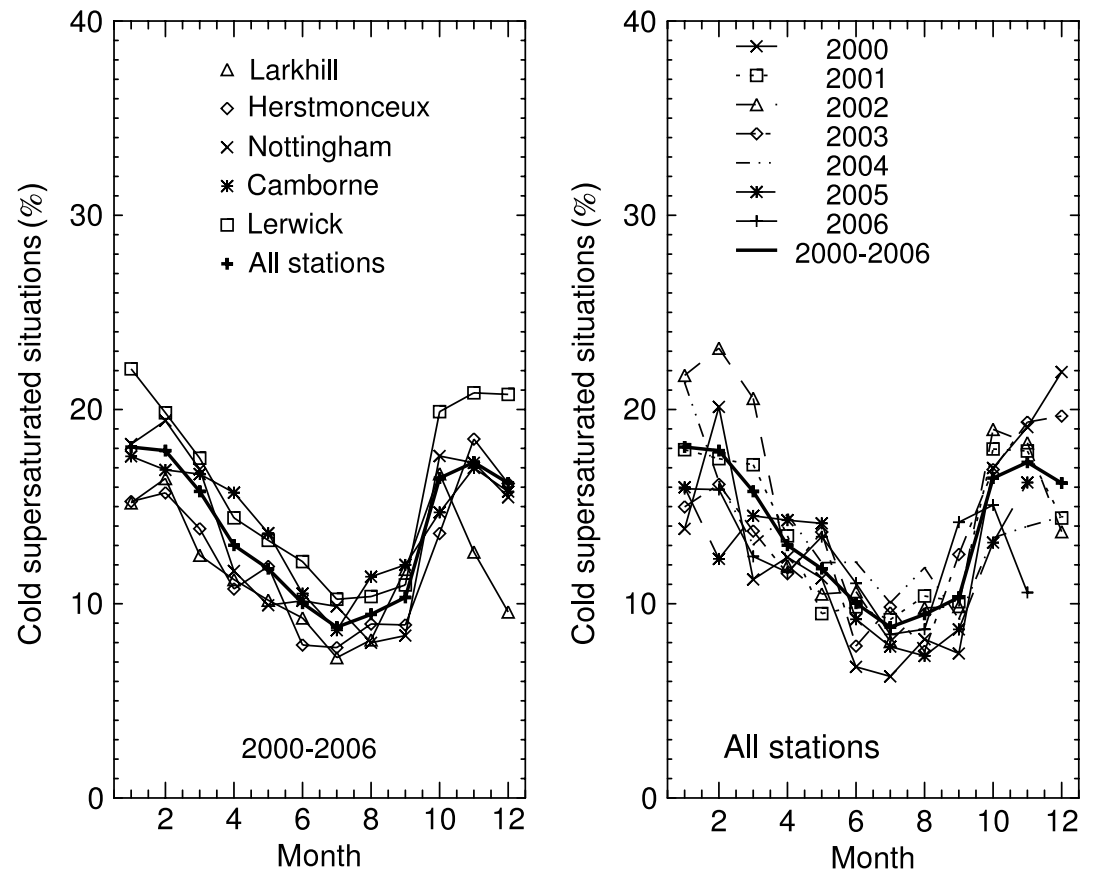

Figure 3. Probability of a CISSR in the troposphere as a function of the calendar month, averaged over the years 2000-2006 for each separate radiosonde station (left) and averaged over all stations showing each individual year (right). The probability is computed as the number of radiosonde measurements with $T<-40{ }^{\circ} \mathrm{C}$ and $\mathrm{RH}_{\text {ice }}>100 \%$ divided by all measurements between $6-16 \mathrm{~km}$ height.

Figure 4 shows the percentage of atmospheric profiles with at least one CISSR, as a function of month. The average percentage of profiles with at least one supersaturated atmospheric layer colder than $-40{ }^{\circ} \mathrm{C}$ is $42.5 \%$. The individual values for the years 2001-2005 lie between $40.5 \%$ and $45.1 \%$. The year 2000 shows the lowest value at $38.9 \%$ which is due to very low values at Herstmonceux, which also shows similarly low values for 2001. The reason for these low values are under investigation. On the other hand, 2006 shows the highest average value of $46.0 \%$. This is perhaps due to the fact that by 2006, Vaisala RS92 radiosondes were used at all stations and correction methods were not yet fully optimized. This assumption is supported by looking in detail at the 2005 results: those stations that already had the new type of sondes in use for some months also show larger values for these periods. A weaker seasonal cycle is visible here which is consistent with results obtained by Spichtinger et al. (2003) for a study of occurrence of supersaturation over Lindenberg, Germany, in 2000/2001. Spichtinger et al. (2003) find average values for the occurrence of supersaturation, calculated similarly to the above values for the five UK stations, of about $28 \%$. This is not in contradiction with the results of this study, which for 2000 vary between $17 \%$ and $48 \%$ depending on the station.

Figure 4 (left) shows that the seasonal cycle is broadly similar at each individual station. From this relatively small sample of years, we are not able to assert whether some differences between the stations, e.g. the relatively high probabilities measured at Lerwick, are significant.

Figure 5 shows the probability distribution of a CISSR as a function of the height of its centre for both summer
(June-August) and winter (December-February). The most likely values are slightly higher for summer $(\sim 10 \mathrm{~km})$ than for winter $(\sim 9.5 \mathrm{~km})$. The probabilities of cold supersaturated layers at altitudes smaller than $10 \mathrm{~km}$ are larger in winter than in summer, while at higher altitudes the probabilities for summer and winter are very similar, leading to a wider distribution in winter. This is also shown in Figure 6 where the distributions of layer widths are shown separately for summer and winter for RS80-H and RS92 radiosondes, respectively. The RS92 sondes seem to be able to measure smaller layer widths, an effect especially pronounced in winter. This may be attributed to the facts that RS92 sondes are less affected by sensor icing and that the RS80-H sondes have a slower response than RS92 sondes.

Table II displays the results on the mean heights and widths of cold supersaturated atmospheric layers. For all these results the standard resolution data has been used; they therefore refer to layers of a minimum width of $\sim 150 \mathrm{~m}$. The thicker layers during winter explain the difference between Figures 3 and 4. Although the probability of at least one CISSR occurring is approximately constant throughout the year, the layers that occur during winter are thicker and there is a higher probability of encountering one at any given height.

The characteristics of CISSRs given in this table were also computed for RS80-H and RS92 measurements separately. As mentioned above, CISSRs measured by RS92 sondes are thinner on average by about $20 \%$, but their average altitudes are the same within $\sim 5 \%$ for all cases considered in Table II. 

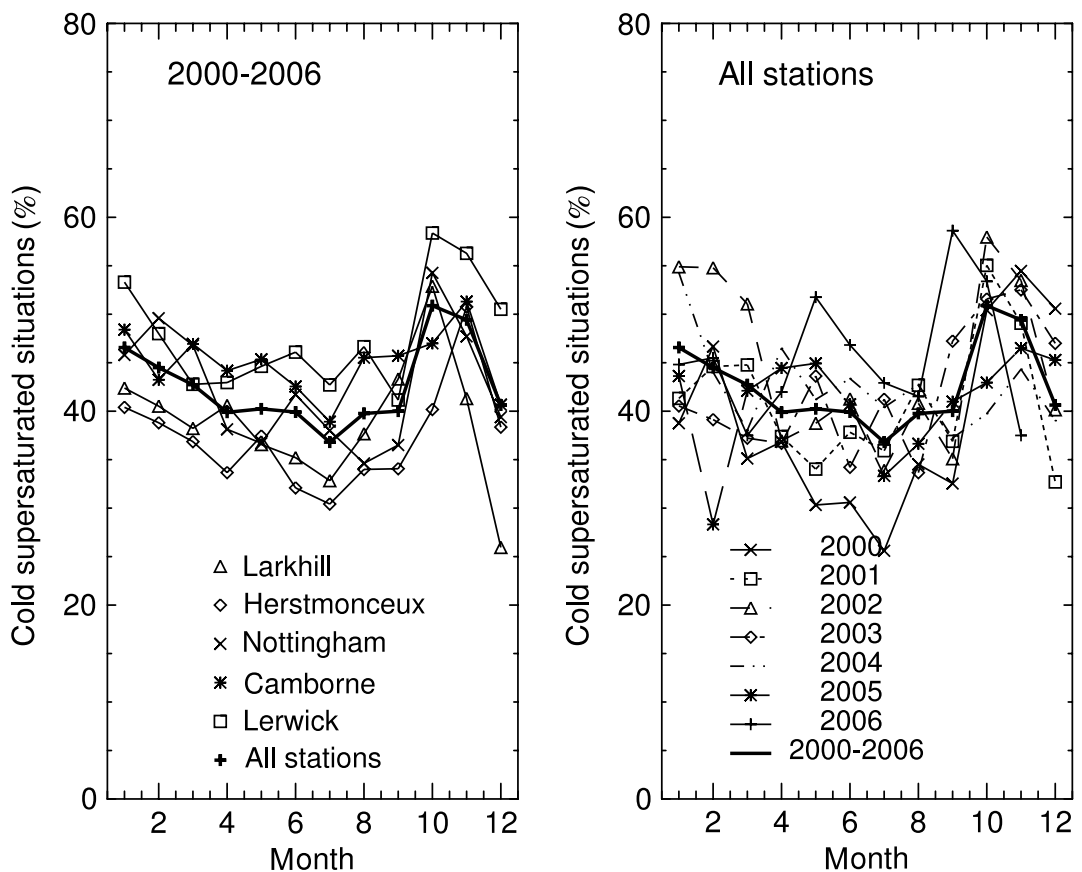

Figure 4. Probability that at least one CISSR layer can be observed in the troposphere as a function of calendar month averaged over the years 2000-2006 for each separate radiosonde station (left) and averaged over all stations for individual years (right). The probability is computed as the number of radiosonde ascents with at least one measurement with $T<-40{ }^{\circ} \mathrm{C}$ and $\mathrm{RH}_{\text {ice }}>100 \%$.

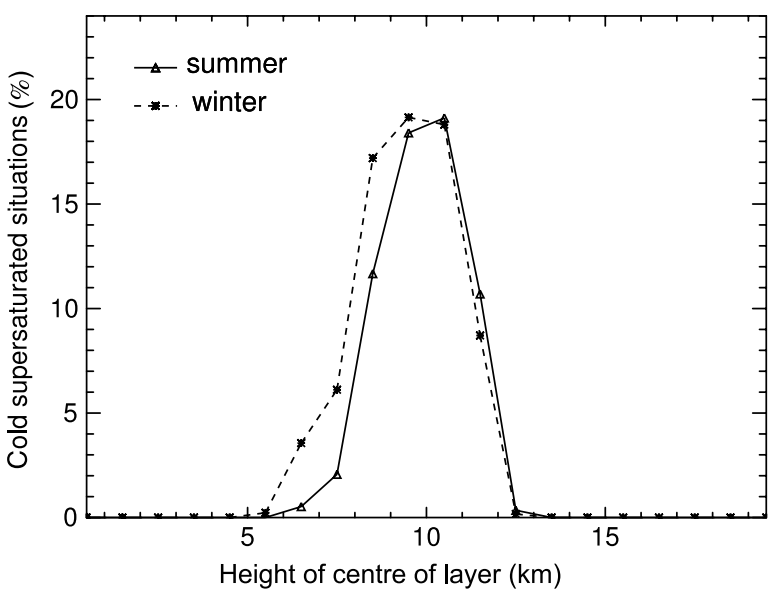

Figure 5. Probability of a CISSR in the troposphere as a function of the height of the layer's centre averaged over the years 2000-2006 for summer (JJA) and winter (DJF) months. The probability is computed as the number of radiosonde measurements with $T<-40^{\circ} \mathrm{C}$ and $\mathrm{RH}_{\text {ice }}>100 \%$ compared to all measurements.

\section{Visual observations of persistent contrails over Reading and their correlation with identified supersaturated regions}

Since July 2004, routine observations were carried out at least four times a day (at 0900, 1200, 1500 and $1800 \mathrm{~h}$ ) to see whether persistent contrails occurred over Reading. A small subset of these observations has already been used in previous publications to validate radiosonde measurements (Stuber et al., 2006) and a new ice nucleation scheme in the ECMWF integrated forecast system (Tompkins et al., 2007). Twenty-nine months of observations (July 2004-November 2006) have been acquired and used to evaluate the forecast skill for persistent contrail occurrence, hence CISSRs, using radiosonde data. The visual observations have been compared to radiosonde data that have been recorded within \pm 1 hour at the five different stations introduced in Section 2.

Typical vertical profiles of relative humidity with respect to ice for Larkhill are shown in Figure 7. The left graph of Figure 7 corresponds to a case when persistent contrails were observed in Reading, while the right-hand figure corresponds to a case when no contrails were observed. The full lines in both graphs correspond to situations where the temperature was $<-40{ }^{\circ} \mathrm{C}$, and the vertical line at $\mathrm{RH}_{\text {ice }}=100 \%$ indicates the threshold for ice supersaturation. In other words, the potential for the existence of persistent contrails is predicted if the full line crosses this threshold. For the cold part of the profile, data before correction is also shown (dash-dotted line) to indicate the size of the correction.

The observations over Reading have been classified into 'yes' and 'no' events. A 'yes' event means that at least one persistent contrail was observed at the given time. 'Persistent' in this context was defined to mean that a non-dissipating contrail had been observed, but no aircraft were visible. A 'no' event means that either an aircraft failed to form a contrail or formed one that dissipated immediately, or neither aircraft nor contrails were observed for several minutes. If the sky was overcast, no observations were recorded. Due to the location of Reading in the entrance to the North Atlantic flight corridor, the flight density is very high (e.g. Eyers et al., 2004). There is therefore a high probability that if the atmospheric conditions are favourable for 

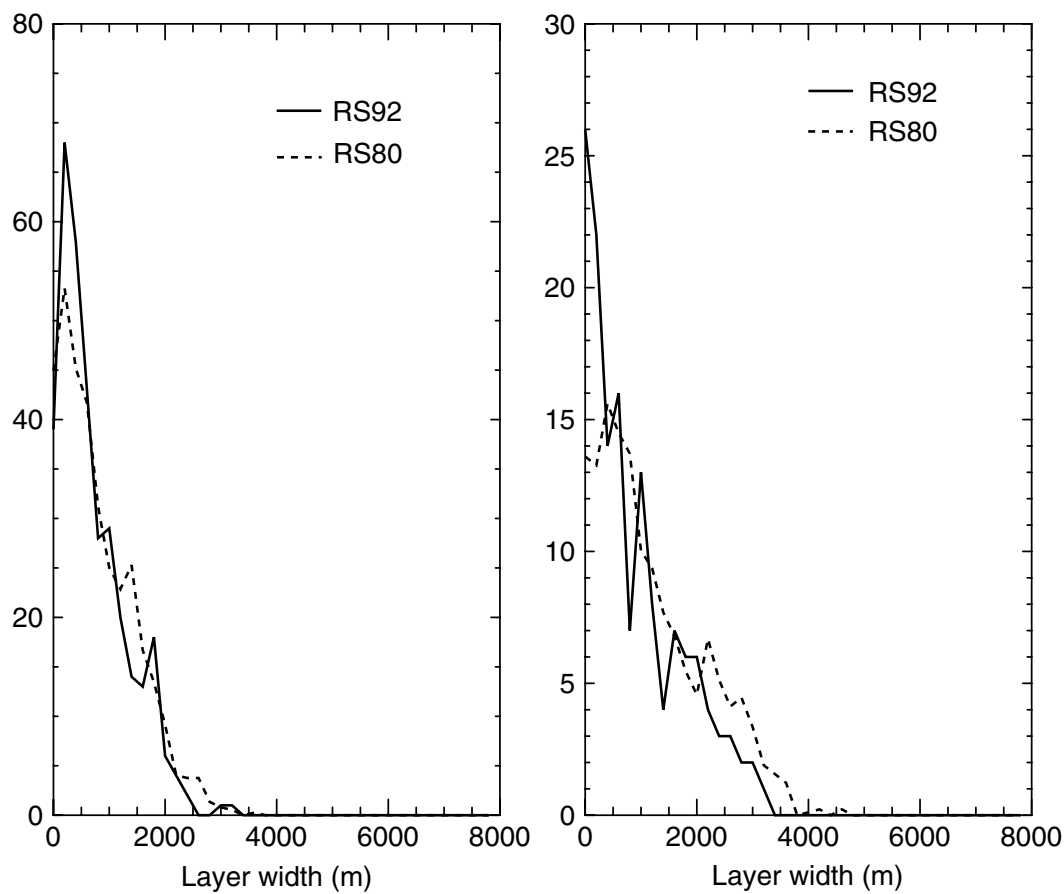

Figure 6. Distribution of the width of the tropospheric supersaturated cold atmospheric layers for summer (left) and winter (right). Full lines show results for RS92 radiosondes while dashed lines correspond to RS80H sondes.

Table II. Characteristics of cold supersaturated atmospheric layers averaged over all five stations and over the years 2000-2006. Separate results for summer (JJA) and winter (DJF) months are also shown.

\begin{tabular}{llccc}
\hline & & All & Winter & Summer \\
\hline Width (mean) & $(\mathrm{hPa})$ & 45 & 58 & 34 \\
& $(\mathrm{~km})$ & 1.1 & 1.3 & 0.9 \\
Centre height (mean) & $(\mathrm{hPa})$ & 305 & 330 & 281 \\
& $(\mathrm{~km})$ & 9.0 & 8.3 & 9.7 \\
Mean and rms of Gauss fit & & $8.8 \pm 1.1$ & $8.4 \pm 1.0$ & $9.7 \pm 0.8$ \\
Base height (mean) & $(\mathrm{hPa})$ & 328 & 359 & 297 \\
& $(\mathrm{~km})$ & 8.4 & 7.7 & 9.2 \\
Top height (mean) & $(\mathrm{hPa})$ & 282 & 301 & 264 \\
& $(\mathrm{~km})$ & 9.5 & 8.9 & 10.1 \\
Number of layers per profile & & 0.3 & 0.3 & 0.3 \\
Number of layers per profile if $>0$ & & 1.1 & 1.1 & 1.1 \\
\hline
\end{tabular}

persistent contrails, there will be an aircraft flying at the corresponding height, and, taking into account the lifetimes of persistent contrails of up to several hours, there will be at least one visible at a given time. Figure 8 shows the distribution of pressure levels at which CISSRs occur for the Larkhill radiosonde measurements. The values correspond to the top of the highest layer of each profile, but only layers which extend to pressures below $150 \mathrm{hPa}$ are considered. The full and dashed lines correspond to cases when a persistent contrail was observed or not observed, i.e. to the 'yes' and 'no' events, respectively. It can be seen from this figure that if a CISSR existed at high altitudes $(p<230 \mathrm{hPa})$ a persistent contrail was almost always observed while the correlation for CISSRs at lower altitudes is less strong. In only about $50 \%$ of the lower altitude cases, a persistent contrail was observed. This may reflect the fact that the most likely cruise altitude for aircraft is around $10-11 \mathrm{~km}$.

A statistical analysis of all such correlated observations and measurements was performed creating $2 \times 2$ contingency tables, with the four parameters:

$a$ The number of events when a contrail was observed and predicted by the radiosondes (so-called hit).

$b$ The number of events when no contrail was observed but radiosonde data shows favourable conditions (false alarm).

$c$ The number of events when a contrail was observed but the radiosonde data does not predict favourable conditions (miss). 

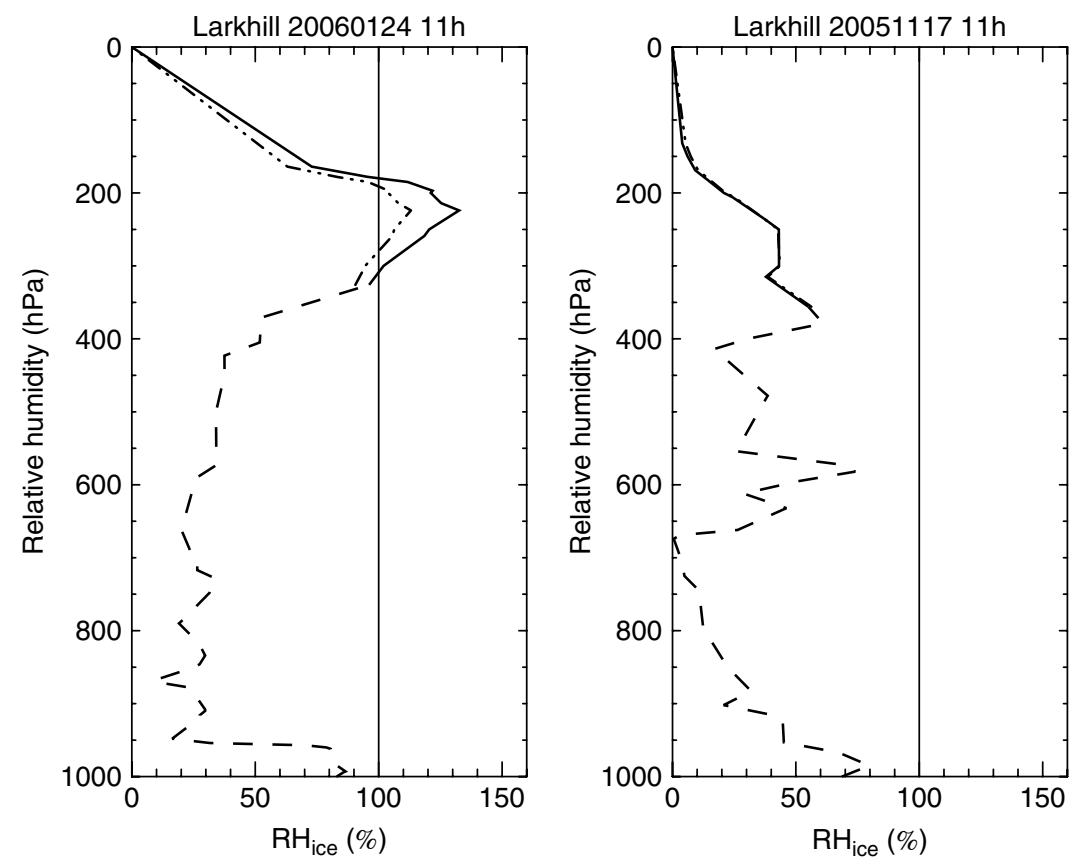

Figure 7. Vertical profiles of relative humidities with respect to ice measured at Larkhill. Left (right): Case when (no) persistent contrails have been observed over Reading. Full line: Corrected data at $T<-40^{\circ} \mathrm{C}$; dashed line: corrected data at $T>-40^{\circ} \mathrm{C}$; dash-dotted line: uncorrected data at $T<-40^{\circ} \mathrm{C}$.

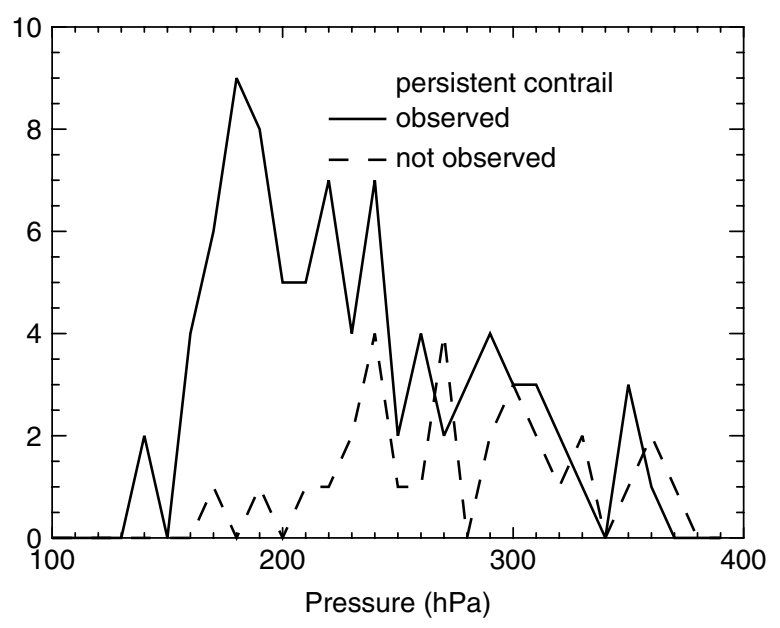

Figure 8. Pressure levels at which CISSRs are measured at Larkhill using radiosonde data (July 2004-November 2006). Full line: a persistent contrail was observed over Reading within \pm 1 hour of the measurement; dashed line: no persistent contrail was observed.

$d$ The number of events when no contrail was observed and the radiosonde data shows no favourable conditions (no-hit).

Obviously a good prediction implies that $a$ and $d$ are large while $b$ and $c$ should be small. The results of the comparison between visual observation and radiosonde data are shown in Table III. The best correlation between forecast and observation is expected for Larkhill forecasts using corrected radiosonde data. In fact, 'yes' events are predicted correctly in $71 \%$ and 'no' events in $83 \%$ of the cases. Reasons for misses as well as false alarms are the distance of $63 \mathrm{~km}$ and time difference of up to
1 hour between observation and measurement as well as measurement errors, e.g. insufficient dry-bias correction or over-correction for misses and false alarms. A miss could also occur because a thin CISSR (Figure 2) is present but not represented in the standard resolution data. False alarms may be further explained by the fact that no aircraft at the correct height of the CISSR had been passing over Reading at the time of observation or by the icing effect which would lead to an overestimate of contrail predictions. For stations close to the observation point, however, this latter effect should be less important because icing predominately occurs when many low or medium level clouds are present. Since it is not possible to observe contrails in overcast situations, the sample of radiosonde measurements which are compared to the observations should be less affected by sensor icing than the full sample. For comparison, tables are shown for all five stations and results for uncorrected radiosonde data are given in brackets (Table III). One observes qualitatively, that the larger the distance of the station from Reading the smaller is their predictive power, and predictions are better for corrected than for uncorrected data, as is expected.

\section{Statistical analysis of results}

For a quantitative analysis of the $2 \times 2$ contingency tables, a possible method is to compute the statistical significance of these results using the Odds ratio $O$, proposed by Stephenson (2000) for use in meteorological applications. The Odds ratio is defined as $O=(a \times$ $d) /(b \times c)$. It is 1 for the null hypothesis, i.e. no correlation between observation and prediction, $>1$ in 
case of a positive correlation, and $<1$ for a negative correlation. The natural logarithm of $O$ is asymptotically Gaussian distributed, with a standard deviation of $\sigma=$ $\sqrt{1 / a+1 / b+1 / c+1 / d}$.

Results for the Odds ratio $O, \ln O$ and its standard deviation and $P_{O}$, the probability to observe a configuration for the contingency table that is more extreme than that observed on a purely random basis, are given in Table IV. For comparison, other measures of the skill of the predictions are also shown: the probability according to Fisher's exact test $P_{\mathrm{FET}}$ (Fisher, 1922), the hit-rate (HR) $a /(a+c)$, the false-alarm-rate (FAR) $b /(b+d)$ and the Peirce skill score (Peirce, 1884) which is equal to HR-FAR and is also referred to as the Hanssen-Kuipers score (Hanssen and Kuipers, 1965). This score gives a measure of the accuracy for both 'yes' and 'no' events. It ranges from -1 to 1 , and is 0 for a random forecast. It is -1 if neither 'yes' nor 'no' events are predicted correctly.

For Larkhill, which at $63 \mathrm{~km}$ is the closest to Reading, a clear match between observations and predictions is observed. The probabilities $P_{O}$ and $P_{\mathrm{FET}}$, which can be seen as the probability of the measured contingency table being obtained by a random forecast, i.e. a forecast without any skill, are extremely small. The HR at $70.9 \%$ is much higher than the FAR at $17.3 \%$ and the Peirce skill score is clearly greater than zero, indicating a skill to correctly predict 'yes' and 'no' events.

On the other hand, a forecast for persistent contrails over Reading derived from radiosonde data at Lerwick has no skill at all. Hit- and false-alarm-rates are about equal, probabilities $P_{O}$ and $P_{\text {FET }}$ are close to $100 \%$ and the Peirce skill score is around 0, indicating no forecasting skill. Given the distance of Lerwick to Reading of $\sim 1000 \mathrm{~km}$, this is unsurprising. The other three stations, at distances of $111-332 \mathrm{~km}$, show intermediate results. In fact, the results for forecasts from Herstmonceux and Nottingham are quite similar and still demonstrate skill, with HRs of more than two times larger than the FARs and a Peirce skill score of 0.34 and 0.38 , respectively. This indicates that the average horizontal extent of supersaturated atmospheric areas is of the order of radius 100-200 km. Even the forecasts from Camborne, which involve more than $300 \mathrm{~km}$ distance, still seem to have a small skill. This may be helped by the two facts that the measurements at Camborne are always made at 11:00 GMT, i.e. 1 hour before observation time at Reading, and secondly predominant conditions at Cambourne are that of south-westerly winds. These indications for the horizontal extent of CISSRs are in good agreement with values derived from the MOZAIC (Measurement of Ozone by Airbus In-service aircraft) campaign (Gierens and Spichtinger, 2000), where average distances flown in ice-supersaturated regions by commercial aircraft were measured to be $150 \mathrm{~km}$ on average, with a standard deviation of $250 \mathrm{~km}$. Values of several thousand kilometres have even been recorded.

The same quantities using uncorrected radiosonde data for the predictions are also shown in Table IV in the

Table III. $2 \times 2$ contingency tables for observations of persistent contrails over Reading compared to forecasts derived from radiosonde data at different stations. Corrected radiosonde data has been used. Values in brackets were derived from uncorrected data.

\begin{tabular}{|c|c|c|c|c|c|c|c|c|c|c|}
\hline \multirow[b]{3}{*}{ Observed } & \multirow{2}{*}{\multicolumn{2}{|c|}{$\begin{array}{c}\begin{array}{c}\text { Larkhill } \\
\left(1.80^{\circ} \mathrm{W}, 51.20^{\circ} \mathrm{N}\right)\end{array} \\
\text { Predicted }\end{array}$}} & \multirow{2}{*}{\multicolumn{2}{|c|}{$\begin{array}{c}\begin{array}{c}\text { Herstmonceux } \\
\left(0.32^{\circ} \mathrm{E}, 50.89^{\circ} \mathrm{N}\right)\end{array} \\
\text { Predicted }\end{array}$}} & \multirow{2}{*}{\multicolumn{2}{|c|}{$\begin{array}{c}\begin{array}{c}\text { Nottingham } \\
\left(1.20^{\circ} \mathrm{W}, 53.00^{\circ} \mathrm{N}\right)\end{array} \\
\text { Predicted }\end{array}$}} & \multirow{2}{*}{\multicolumn{2}{|c|}{$\begin{array}{c}\text { Camborne } \\
\left(5.32^{\circ} \mathrm{W}, 50.22^{\circ} \mathrm{N}\right) \\
\text { Predicted }\end{array}$}} & \multirow{2}{*}{\multicolumn{2}{|c|}{$\begin{array}{c}\text { Lerwick } \\
\left(1.18^{\circ} \mathrm{W}, 60.13^{\circ} \mathrm{N}\right) \\
\text { Predicted }\end{array}$}} \\
\hline & & & & & & & & & & \\
\hline & Yes & No & Yes & No & Yes & No & Yes & No & Yes & No \\
\hline Yes & 78 (30) & $32(79)$ & $56(20)$ & 47 (94) & $63(11)$ & $29(80)$ & 66 (17) & $46(92)$ & $48(24)$ & $42(63)$ \\
\hline No & $22(5)$ & 105 (119) & $19(8)$ & 72 (101) & $29(8)$ & $67(110)$ & $45(8)$ & 77 (110) & $55(26)$ & $41(70)$ \\
\hline
\end{tabular}

Table IV. Statistical analysis of the $2 \times 2$ contingency tables derived using corrected radiosonde data for the predictions. For each station, the second line of values shows results using uncorrected radiosonde data.

\begin{tabular}{lrccccrr}
\hline Station (distance to Reading) & $O$ & $\ln O \pm \sigma$ & $P_{O}(\%)$ & $P_{\text {FET }}(\%)$ & HR $(\%)$ & FAR $(\%)$ & Peirce S.S. \\
\hline Larkhill $(63 \mathrm{~km})$ & 11.6 & $2.45 \pm 0.32$ & $10^{-13}$ & $10^{-15}$ & 70.9 & 17.3 & 0.54 \\
& 9.0 & $2.20 \pm 0.50$ & 0.001 & $5 \times 10^{-5}$ & 27.5 & 4.0 & 0.24 \\
Herstmonceux (111 km) & 4.5 & $1.50 \pm 0.33$ & $4 \times 10^{-4}$ & $2 \times 10^{-4}$ & 54.4 & 20.9 & 0.34 \\
& 2.7 & $0.99 \pm 0.44$ & 0.025 & 0.026 & 17.5 & 7.3 & 0.10 \\
Nottingham (168 km) & 5.0 & $1.61 \pm 0.32$ & $4 \times 10^{-5}$ & $2 \times 10^{-5}$ & 68.5 & 30.2 & 0.38 \\
& 3.1 & $1.13 \pm 0.49$ & 0.020 & 0.023 & 12.1 & 6.8 & 0.05 \\
Camborne (332 km) & 2.5 & $0.92 \pm 0.27$ & 0.06 & 0.1 & 58.9 & 36.9 & 0.22 \\
& 2.5 & $0.92 \pm 0.45$ & 0.041 & 0.054 & 15.6 & 6.8 & 0.09 \\
Lerwick (969 km) & 0.8 & $-0.22 \pm 0.30$ & 100 & 66 & 53.3 & 57.3 & -0.04 \\
& 1.3 & $0.26 \pm 0.33$ & 43 & 100 & 27.6 & 27.1 & 0.00 \\
\hline
\end{tabular}


second line for each station. It is clearly seen that these forecasts are worse for all the stations (except Lerwick). However, these four forecasts also have a predictive skill as the HR is clearly larger than the FAR. However, due to the dry-bias of the sondes they are both very low, and persistent contrails are only correctly predicted in $27.5 \%$ of the cases for Larkhill and in less than $20 \%$ from the other stations. This clearly shows that the drybias corrections of the data are necessary.

The corrections for the two different types of radiosondes used, RS80-H and RS92, can also be checked. The statistical analyses from the contingency tables for the two types of sondes are shown for all five stations in Tables V and VI, respectively. Comparing the results for the two different datasets it can be seen that for Larkhill all the skill scores are quite similar for the new and old sondes, but the forecasts based on RS92 sondes are slightly better, as the ratio of HRs and FARs is more favourable. However, there may be a systematic difference with the new sondes being drier even after correction, since both are lower than for the RS80-H sondes which would be consistent with sensor icing affecting RS80-H sondes more than RS92 sondes.

The largest difference between the datasets is observed for Herstmonceux. Here the RS92 sondes clearly provide much poorer quality forecasts, while the Odds ratio and Peirce skill score of the other three stations are very different for RS80-H and RS92. This may indicate that the new sondes at Herstmonceux were not optimally used. However, both hit- and false-alarm rates at Camborne, Nottingham and Lerwick are lower for RS92 than for RS80-H, indicating that the RS92 sondes are systematically drier. Another abnormality in the data from Herstmonceux appears when summer and winter forecasts are checked individually. Comparing observations and forecasts from both sonde types together for the months of June-August and December-February, the results are not significantly different, with the exception of the Herstmonceux forecasts. These show much less skill in winter than in summer, the Odds ratios being 1.9 and 13.8 , respectively.

\section{Conclusions}

It has been shown by comparison to visual observation of persistent contrails that radiosonde humidity measurements can be used to measure ice supersaturation in the upper troposphere, once corrected appropriately for biases of different origins depending on the type of radiosonde. For the more recently introduced RS92 sondes, corrections available in the literature cover only a relatively small range of conditions, and could be improved.

Cold ice-supersaturated atmospheric regions could be identified and verified by visual observations of persistent contrails over Reading, establishing at the same time the necessary condition of the existence of CISSRs for persistent contrails to exist. It has been found that the probability of an ice supersaturation somewhere in the troposphere shows a strong seasonal cycle with a minimum in summer and a maximum in winter. On the other hand, the probability of finding at least one supersaturated layer is approximately constant over the year, indicating that in winter the CISSRs are thicker than in summer, which has also been found directly from the observations. The distribution of layer-widths has a strong peak at about $50 \mathrm{~m}$ and an underlying broader distribution with values up to several kilometres. Furthermore, a statistical analysis of the correlation between the occurrence of ice-supersaturated regions measured by radiosondes (launched at Larkhill and four other sites in the UK) and visual observations of persistent contrails over Reading has been performed, and horizontal extents of the CISSRs of diameters of several hundreds of kilometres could be inferred.

It is still common for models not to allow for ice supersaturation, and they are therefore not suitable for

Table V. Statistical analysis of the $2 \times 2$ contingency tables derived using radiosondes of type RS80-H.

\begin{tabular}{lrcccccc}
\hline Station (distance to Reading) & $O$ & $\ln O \pm \sigma$ & $P_{O}(\%)$ & $P_{\text {FET }}(\%)$ & HR $(\%)$ & FAR $(\%)$ & Peirce S.S. \\
\hline Larkhill $(63 \mathrm{~km})$ & 10.4 & $2.34 \pm 0.50$ & $3 \times 10^{-4}$ & $8 \times 10^{-5}$ & 78.0 & 25.5 & 0.53 \\
Herstmonceux $(111 \mathrm{~km})$ & 11.0 & $2.34 \pm 0.62$ & 0.02 & 0.007 & 78.6 & 25.0 & 0.54 \\
Nottingham $(168 \mathrm{~km})$ & 5.7 & $1.74 \pm 0.42$ & 0.003 & 0.004 & 76.4 & 36.4 & 0.40 \\
Camborne $(332 \mathrm{~km})$ & 3.3 & $1.19 \pm 0.35$ & 0.07 & 0.03 & 67.2 & 47.3 & 0.20 \\
Lerwick $(969 \mathrm{~km})$ & 0.7 & $-0.36 \pm 0.43$ & 100 & 40 & 63.3 & 72.0 & -0.09 \\
\hline
\end{tabular}

Table VI. Statistical analysis of the $2 \times 2$ contingency tables for forecast using only radiosondes of type RS92.

\begin{tabular}{lrcccccc}
\hline Station (distance to Reading) & \multicolumn{1}{c}{$O$} & $\ln O \pm \sigma$ & $P_{O}(\%)$ & $P_{\mathrm{FET}}(\%)$ & HR $(\%)$ & FAR $(\%)$ & Peirce S.S. \\
\hline Larkhill $(63 \mathrm{~km})$ & 14.9 & $2.70 \pm 0.44$ & $8 \times 10^{-8}$ & $5 \times 10^{-10}$ & 66.7 & 11.8 & 0.55 \\
Herstmonceux $(111 \mathrm{~km})$ & 3.6 & $1.28 \pm 0.41$ & 0.18 & 0.16 & 45.3 & 18.6 & 0.27 \\
Nottingham $(168 \mathrm{~km})$ & 4.7 & $1.55 \pm 0.50$ & 0.19 & 0.23 & 56.8 & 22.0 & 0.35 \\
Camborne $(332 \mathrm{~km})$ & 3.3 & $1.19 \pm 0.46$ & 0.97 & 0.015 & 46.7 & 20.8 & 0.26 \\
Lerwick $(969 \mathrm{~km})$ & 1.0 & $0.0 \pm 0.44$ & 2.2 & 100 & 41.5 & 41.3 & 0.002 \\
\hline
\end{tabular}


direct prediction of the occurrence of persistent contrails. Efforts have been made to correct this shortcoming in a number of climate and numerical weather prediction (NWP) models (e.g. Wilson and Ballard, 1999; Lohmann and Kärcher, 2002; Gettelman and Kinnison, 2006; Tompkins et al., 2007). This work indicates that if corrected radiosonde data are used in conjunction with data on the distribution of aircraft, the frequency of occurrence of contrails could be quite reliably deduced, subsequently allowing an evaluation of these new supersaturation schemes.

\section{Acknowledgements}

This work was performed under the 'Low Emissions Effects Aircraft' project funded by Airbus and the UK Department of Trade and Industry. It was completed under the European Commission's Framework 6 Integrated Project QUANTIFY. We thank the British Atmospheric Data Centre and A. Tompkins (ECMWF) for providing the radiosonde and synoptic data, N. Stuber, P. Spichtinger and K. Gierens for fruitful discussions and two referees for important comments.

\section{References}

Appleman H. 1953. The formation of exhaust contrails by jet aircraft Bull. Am. Meteorol. Soc. 34: 14-20.

Eyers C, Norman P, Middel J, Plohr M, Michot S, Atkinson K, Christou R. 2004. AERO2k Global Aviation Emissions Inventories for 2002 and 2025. QinetiQ Ltd., Tech. Rep. QINETIQ/04/01113.

Fisher R. 1922. On the interpretation of $\chi^{2}$ from contingency tables, and the calculation of P. J. Roy. Statist. Soc. 85: 87-94.

Gettelman A, Kinnison DE. 2006. The global impact of supersaturation in a coupled chemistry-climate model. Atmos. Chem. Phys. 7: $1629-1643$.

Gierens K, Spichtinger P. 2000. On the size distribution of icesupersaturated regions in the upper troposphere and lowermost stratosphere. Ann. Geophys. 18: 499-504.

Hanssen A, Kuipers W. 1965. On the relationship between the frequency of rain and various meteorological parameters. Meded. Verh. 81: 2-15.

IPCC. 1999. Aviation and the Global Atmosphere - A Special Report of IPCC Working Groups I and III. Penner JE (ed). IPCC, Tech. rep.

Jackson A, Newton B, Hahn D, Bussey A. 2001. Statistical contrail forecasting. J. Appl. Meteorol. 40: 269-279.

Jensen EJ, Toon OB, Kinne S, Sachse GW, Anderson BE, Chan KR, Twohy CH, Gandrud B, Heymsfield AJ, Miake-Lye RC. 1998. Environmental conditions required for contrail formation and persistence. J. Geophys. Res. 103: 3929-3936.

Kley DJR III, Phillips EC. 2000. SPARC assessment of upper tropospheric and stratospheric water vapour. SPARC, Tech. Rep. 2.

Lohmann U, Kärcher B. 2002. First interactive simulations of cirrus cloud formed by homogeneous freezing in the ECHAM general circulation model. J. Geophys. Res. 107: AC-8 10.1029/2001JD000,767.

Mannstein H, Schumann U. 2005. Aircraft induced contrail cirrus over Europe. Meteorol. Zeitschrift 14: 549-554.

Marquart S, Ponater M, Mager F, Sausen R. 2003. Future development of contrail cover, optical depth and radiative forcing: Impacts of increasing air traffic and climate change. J. Climate 16: 2890-2904.

Meerkötter R, Schumann U, Doelling D, Minnis P, Nakajima T, Tsushima Y. 1998. Radiative forcing by contrails. Ann. Geophys. 17: $1080-1094$.

Miloshevich LM, Vömel H, Paukkunen A, Heymsfield A, Oltmanns SJ. 2001. Characterization and correction of relative humidity measurements from Vaisala RS80-A radiosondes at cold temperatures. J. Atmos. Ocean. Tech. 18: 35-156.
Miloshevich LM, Paukkunen A, Vömel H, Oltmanns SJ. 2004. Development and validation of a time-lag correction for Vaisala radiosonde humidity measurements. J. Atmos. Ocean. Tech. 21: $1305-1327$.

Minnis P, Young D, Garber D, Nguyen L, Smith W Jr., Palikonda R. 1998. Transformation of contrails into cirrus during SUCCESS. Geophys. Res. Lett. 25: 1157-1160.

Minnis P, Schumann U, Doelling D, Gierens K, Fahey D. 1999. Global distribution of contrail radiative forcing. Geophys. Res. Lett. 26: 1853-1856.

Minnis P, Ayers J, Nordeen M, Weaver S. 2003. Contrail frequency over the United States from surface observations. J. Climate 16: 3447-3462.

Moss SJ. 1999. The testing and verification of contrail forecasts using pilot observations from aircraft. Meteorol. Appl. 6: 193-200.

Myhre G, Stordal F. 2001. On the tradeoff of the solar and thermal infrared impact of contrails. Geophys. Res. Lett. 28: 3119-3122.

Peirce C. 1884 . The numerical measure of the success of predictions. Science 12: 453-545.

Sausen R, Isaksen I, Grewe V, Hauglustaine D, Lee DS, Myhre G, Köhler MO, Pitari G, Schumann M, Stordal F, Zerefos C. 2005. Aviation radiative forcing in 2000: An update on IPCC (1999). Meteorol. Zeitschrift 14: 555-561.

Schmidt E. 1941. Die Entstehung von Eisnebel aus den Auspuffgasen von Flugmotoren. Schriften der Deutschen Akademie der Luftfahrtforschung 44: 1-15.

Schröder F, Kärcher B, Duroure C, Ström J, Petzold A, Gayet J-F, Strauss B, Wendling P, Borrmann S. 2000. On the transition of contrails into cirrus clouds. J. Atmos. Sci. 57: 464-480.

Schumann U. 1996.. On conditions for contrail formation from aircraft exhausts. Meteorol. Zeitschrift 5: 4-25.

Schumann U. 2000. Influence of propulsion efficiency on contrail formation. Aerosp. Sci. Technol. 4: 391-401.

Simmons AJ, Gibson JK. 2000. The ERA-40 project plan. Era-40 Project Report Series, Tech. Rep. 1.

Soden BJ, Lanzante RJ. 1996. An assessment of satellite and radiosonde climatologies of upper-tropospheric water vapor. J. Climate 9: 235-1250.

Sonntag D. 1994. Advancements in the field of hygrometry. Meteorol. Zeitschrift 3: 51-66.

Spichtinger P, Gierens K, Leiterer U, Dier H. 2003. Ice supersaturation in the tropopause region over Lindenberg, Germany. Meteorol. Zeitschrift 12: 143-156.

Stephens GL, Jackson DL, Wittmeyer I. 1998. Global observations of upper-tropospheric water vapor derived from TOVS radiance data. J. Climate 9: 305-326.

Stephenson DB. 2000. Use of the 'odds ratio' for diagnosing forecast skill. Weather and Forecasting 15: 221-232.

Stubenrauch CJ, Schumann U. 2005. Impact of air traffic on cirrus coverage. Geophys. Res. Lett. 32: L14813 DOI: 10.1029/2005GL022,707.

Stuber N, Forster P, Rädel G, Shine K. 2006. The importance of the diurnal and annual cycle of air traffic for contrail radiative forcing. Nature 441: 864-867.

Stuefer M, Meng X, Wendler G. 2005. MM5 Contrail Forecasting in Alaska. Mon. Weather Rev. 133: 3517-3526.

Tompkins AM, Gierens K, Rädel G. 2007. Ice supersaturation in the ECMWF integrated forcast system. Q. J. R. Meteorol. Soc. 133: 53-63.

Vaughan G, Cambridge C, Dean L, Phillips A. 2006. Water vapour and ozone profiles in the midlatitude upper troposphere. Atmos. Chem. Phys. 5: 963-971.

Vömel H, Selkirk H, Miloshevich L, Valverde-Canossa J, Valdès J, Kyrö E, Kivi R, Stolz W, Peng G, Diaz JA. 2007. Radiation dry bias of the Vaisala RS92 humidity sensor. J. Atmos. Ocean. Tech. 24: 953-963.

Walters MK, Shull JD, Asbury RP. 2000. A comparison of exhaust condensation trail forecast algorithms at low relative humidity. $J$. Appl. Meteorol. 39: 80-91.

Wang JH, Cole HL, Carlson DJ, Miller ER, Beierle K, Paukkunen A, Laine TK. 2002. Corrections of humidity measurement errors from the Vaisala RS80 radiosonde - Application to TOGA COARE data. J. Atmos. Ocean. Tech. 19: 981-1002.

Wilson DR, Ballard S. 1999. A microphysical based precipitation scheme for the UK Meteorological Office Unified Model. Q. J. R. Meteorol. Soc. 125: 1607-1636. 